\title{
Developing the control system of a syringe infusion pump
}

\author{
R. Assunção, P. Barbosa, R. Ruge, P. S. Guimarães, J. Alves, I. Silva and M. A. Marques \\ Physics Department, Polytechnic of Porto-School of Engineering, Porto, Portugal
}

\begin{abstract}
Infusion pumps have multiple uses according to their location. According to its use, there is a need to control specific parameters. The objective of this work is to implement and to assembly all the modules of an infusion pump, controlling all the functions. The control was implemented with the microcontroller board based Arduino and a webpage was developed to assist the user to record, retrieve and access information about the operating conditions.
\end{abstract}

Index Terms - Infusion pump, Arduino, webpage, infusion rate, infused volume.

\section{INTRODUCTION}

An infusion pump is an electro medical equipment commonly used in hospitals and in ambulatory to introduce a liquid (other than blood) in a blood vessel, mainly medication or nutrients, since it is a very efficient, rapid and precise method [1][2]. There are several types of infusion pumps distinguished by being either, manual, or semiautomatic or fully automatic. In manual pumps, the flow control depends on the pressure created as result of gravity, since it consists in two liquid reservoirs and a three-way stopcock used to regulate the flow manually, which differs from the semiautomatic type which in turn is automatically controlled by a set of LED/phototransistor counting the number of times the beam is interrupted and emitting alarms. The automatic pumps are used when a better precision is needed. In this case, the infusion pressure is independent of gravity, allowing for greater pressures if necessary. Syringe infusion pumps are used in situations where high precision and low flow are necessary, namely for paediatric cases or in intensive therapies where small volumes of high concentration medication are applied for long periods of time [3].

The flow control may be volumetric or non-volumetric. A volumetric flow control regulates the volume infused per time $(\mathrm{ml} / \mathrm{h})$ as well as the infusing velocity no matter the type of liquid. In a non-volumetric control, the pump controls the number of drops per time (drip rate in drops/min) as well as the infusion velocity. The volume depends on the drop's size, varying with type of equipment, temperature, liquid viscosity and density.

The control circuit can be either analog or digital. In this case, the microprocessor is responsible for interpreting the information recorded on the device, for controlling the infusion mechanism, for interpreting the sensor signals and setting-off the alarms whenever necessary. The control circuits can store information, calculate the dose of the pharmaceutical agents, vary the infusion rate as well as being the interface between the pump and the microcomputer and peripherals. For this reason, the pump control panel consists usually on a keypad, for data setting to define the infusion parameters. The data output is visualized through an alphanumeric display (Liquid Crystal Display - LCD). This display shows information on the infusion in course, the total volume to be infused, the flow rate $(\mathrm{ml} / \mathrm{h}$ or drops $/ \mathrm{min})$, the total and remaining times and some information about the alarms. These alarms control the infusion precision, being set-off in the instant some parameter falls outside the expected operating interval. There are alarms indicating misuse or wear out of some parts, which helps to guarantee the health safety and security of the patient.

\section{CONTROLLLING THE INFUSION PUMP}

In this work, a syringe mechanism was used to serve as the fluid reservoir and to create the necessary pressure for infusion. It uses an endless worm thread to position the plunger, managing in this way the liquid movement. This process is controlled by a stepping motor where the rotation of the motor is transmitted to the endless thread (Figure 1. ). Normally, a spring is used to push the plunger with a constant force, necessary for a stable infusion pressure. This type of infusion generates a continuous high precision flow (with an error below $2 \%$ ).

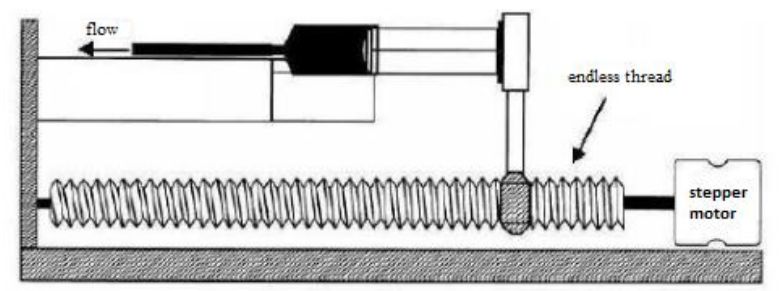

Figure 1. Syringe infusion mechanism [8].

\section{A. Pump and Control System Block Diagram}

The developed system to control the syringe pump is depicted in the block diagram of Figure 2.

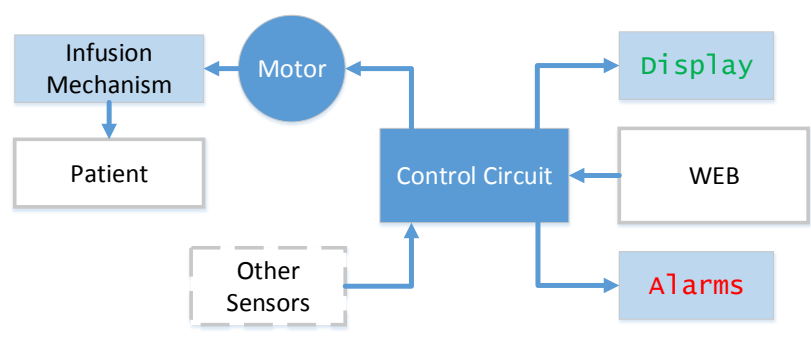

Figure 2. Infusion pump block diagram. 


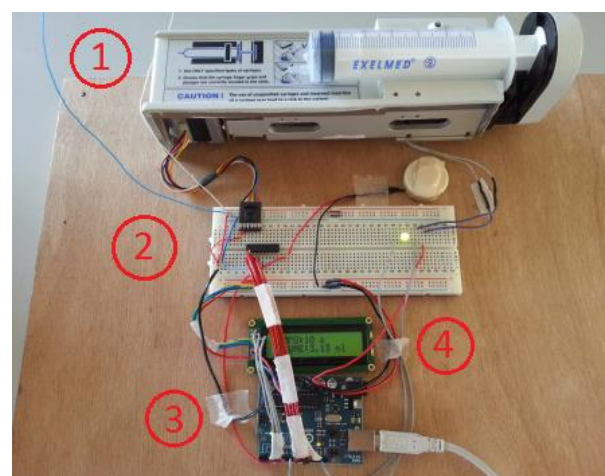

Figure 3. Infusion pump and the developed control system.

The patient is connected to the pump, which in turn is completely controlled by the developed system. The pump sensor and alarms are used and the control circuit manages all the necessary input and output data. Data is sent to the pump through user web interface [6][7]. This block diagram maps on the real system shown in Figure 3.

As depicted, the system is divided in four units:

1. Electrical/mechanical unit of the infusion pump;

2. Module with a stepping motor and its controller and alarms (buzzers and syringe presence led);

3. Arduino module controlling the operation of the pump;

4. Display LCD for visual feedback of the information.

Introducing all the control parameters in the web interface, the information is processed in the microcontroller and the pump is set to work as defined.

\section{B. Web Interface}

Through the web interface, the different infusion parameters are sent to the Arduino [4], which communicates with the pump through the serial port. This interface also allows managing the patients' records by accessing their electronic medical record, thus allowing the health professionals to have more detailed information on the patient as seen on Figure 4. All the information [5] sent to the Arduino, as well as the data related to the patient and the health professional operating the equipment is stored in a database developed in easyphp.

\begin{tabular}{l|l|l|}
$\begin{array}{l}\text { Lista Infusoes: Paula Resende } \\
\text { Medicamento }\end{array}$ & Data \\
\hline Anfotericina & 10 & $2013-02-27$ \\
\hline Ciclofosfamida & 22 & $2013-03-04$ \\
\hline Ciclofosfamida & 5 & $2013-06-28$ \\
\hline Ganciclovir & 2 & $2013-06-28$ \\
\hline Anfotericina & 10 & $2013-06-28$ \\
\hline \multicolumn{2}{|c|}{ Nova infusao } & Voltar \\
\hline
\end{tabular}

Figure 4. Web interface showing the list of medication for a certain patient.

\section{Microcontroller Arduino}

After receiving data from the web interface, the Arduino module calculates the different infusion parameters necessary to set the pump operating mode.

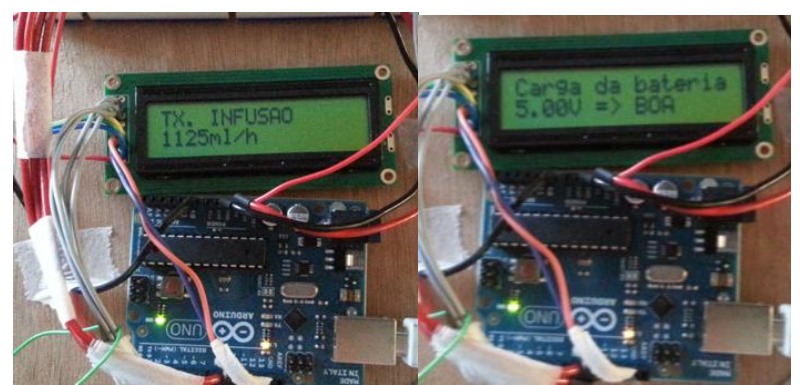

Figure 5. LCD display showing the infusion rate (left) and the battery level (right).

The several alarms are also controlled by this microcontroller. One of the alarms indicates the absence of the syringe, not allowing the infusion if set-off. There are alarms corresponding to the end of the infusion (acoustic alarm) and also to indicate the battery voltage level. All this information is also sent to the LCD display so that the user can visualize what is going on (Figure 5 .

\section{CONCLUSIONS}

The system developed allows to controlling all the parameters necessary to the syringe infusion pump. The mechanical parts used were part of the original pump but the control hardware and the user web interface was completely designed. Apart from the infusion parameters, all the alarms triggered during an infusion, the battery level - which are parameters related to the equipment, the health professional handling the pump and the medical records related to the patient are also recorded in a database for later information. This system could also be improved, mainly the interface with the mechanical part and the microcontroller, specifically inserting a numerical keypad and a command pushbutton to better control the infusion pump, deal with different syringes for specific volumetric flows, and other aesthetic details. Due to time restraints, more emphasis was given on the development of the connections to the database and remote controlling the pump.

\section{REFERENCES}

[1] John G. Webster, "Medical Instrumentation Application and Design", 4th Ed., Wiley, Feb. 2009.

[2] Joseph D. Bronzino, "The Biomedical Engineering Handbook - Medical devices and Systems", $3^{\text {rd }}$ Ed. CRS Press, 2006

[3] https://www.ecri.org/ES/Documents/174961.pdf, "Ambulatory Infusion Pumps", accessed: April 2013

[4] www.arduino.cc, accessed: April 2013

[5] Bemmel, J., Bemmel J. Van, Mark A. Musen, "Handbook of Medical Informatics", Springer, 1997

[6] P. Morville and L. Rosenfeld, "Information Architecture for the World Wide Web: Designing Large-Scale Web Sites”, 2 ${ }^{\text {nd }}$ Ed., O'Reilly, 2002

[7] A. Muller and M. I. Scwartzbach, "An introduction to XML and WEB Technologies", Addison-Wesley, 2006

[8] Anders Muller and Michael I. Scwartzbach, "Equipamentos Medico-Hospitalares e o Gerenciamento da Manutenção", Addison-Wesley, 2006. 